\title{
Cinemeducation: a teaching-learning tool to teach professionalism and ethics in medical undergraduates
}

\author{
Prakruti Parth Patel*, Anuradha Mihir Gandhi, Chetna Kalpan Desai
}

Department of Pharmacology, B. J. Medical College, Ahmedabad, Gujarat, India

Received: 21 November 2021

Revised: 05 December 2021

Accepted: 16 December 2021

\section{*Correspondence:}

Dr. Prakruti Parth Patel,

Email: prakrutiparth@yahoo.co.in

Copyright: () the author(s), publisher and licensee Medip Academy. This is an open-access article distributed under the terms of the Creative Commons Attribution Non-Commercial License, which permits unrestricted non-commercial use, distribution, and reproduction in any medium, provided the original work is properly cited.

\begin{abstract}
Background: The study was undertaken in II year medical students to sensitize and make student competent for professionalism and ethics to maintain respect for patients, colleagues and society and role of Informed Consent in a clinical trial using Cinema-education

Methods: A brief lecture about professionalism and ethics and hands-on training to write reflections was conducted. During session, the knowledge gained and attitudes were checked by pre-test questionnaire. In the Session the students were shown short movie clips that portray on professionalism and ethics which highlight doctor patient relationship in context of maintaining respect of patient, colleagues and society and ethical aspects of informed consent in a clinical trial. The Post session was assessed by a role play, post-test, feedback and reflection writing and analyzed using content and narrative analysis.

Results: Respect towards patients and co-workers and taking informed consent were the positive reflections while treating patients as a subject and giving incomplete information about the trial were pointed out as negative aspect of the movie clip. Majority of the students agreed that cinemeducation had cleared doubts, gave better understanding, stimulated their interest and motivated to learn about professionalism and Ethics. Through role play as assessment the students were able to correctly pick up the scenario, identify the issues related to the role play and were able to give solution to the problem portrayed.

Conclusions: Cinemeducation is an indispensable teaching learning tool to understand about patients feelings, role of communication and to teach empathy, ethical aspects in patient care.
\end{abstract}

Keywords: Cinemeducation, Professionalism, Ethics, Student feedback, Role play

\section{INTRODUCTION}

Professionalism is the attributes, behaviours, commitments, values, and goals that characterize a profession. In medical profession, it encompasses strong societal role and involves emotional component too. ${ }^{1}$ The attributes and behaviours of professionalism are accountability, altruism, commitment to excellence, compassion, integrity, respect, responsiveness, sensitivity to diversity, and sound ethics. Ethics is the study of morality careful and systematic analysis of moral decisions and behaviors and practicing those decisions.
Medical ethics focuses primarily on issues arising out of the practice of medicine. ${ }^{2}$ Medical ethics focuses primarily on issues arising out of the practice of medicine. As a member of medical profession, a physician must recognize responsibility to patients first and foremost, as well as to society, to other health professionals, and to self. Ethics are also important in the conduct of medical research and an essential component of medical practice. Respect for persons, informed consent, and confidentiality are basic principles to the physician-patient relationship. Professionalism and ethics are not taught formally, but are learnt observing the 
teachers and peers. Professionalism and ethics were previously diffused passively to the students as "the hidden curriculum," leaving the learning to chance. However, lately, it has been advocated that graduates need to be formally trained in the concepts of professionalism and ethics. Under graduate medical students in India were not taught professionalism and ethics, in the conventional curriculum. Hence, Indian medical graduate (IMG) may lack the requisite awareness and attitudes to practice professionalism and ethics while treating patients. It has led to incidents of mistrust among patients and the society. Similarly the IMG are less likely to be competent to comprehend the role of informed consent in a clinical research. The AETCOM module incorporates professionalism and ethics using case based scenarios. Movies have been used as a teaching tool in case-based modules and have shown to be efficient and entertaining. ${ }^{3}$ They transform difficult to comprehend into live contextual content. ${ }^{3}$ Movies are emotionally captivating. They accentuate the affective domain of learning too. ${ }^{4}$ Hence, this study was conducted with an aim to teach professionalism and ethics to undergraduate students using cinemeducation as an educational tool.

\section{METHODS}

This prospective, longitudinal, interventional study was carried out to evaluate the impact of cinemeducation on undergraduate second professional year medical students of B. J. medical college from April 2018 to October 2018 in professionalism and Ethics. Consenting undergraduate medical students from second professional year were enrolled in the study after taking written informed consent. All the second professional year medical students who gave consent to be a part of the study were enrolled.

\section{Study tools}

Pre-test: A pre-validated questionnaire was used to test the baseline knowledge and attitudes towards professionalism and ethics among the study participants.

Post-test: The questionnaire was administered to evaluate the change in knowledge and attitudes towards Professionalism and ethics among the participants, following the use of interventional tool, i.e. cinemeducation. Movie clips: Short movie clips that portray professionalism and ethics, after a briefing about the movie and the purpose of showing the same were prepared. "The wit", an English movie that portray professionalism and ethics was chosen for this purpose, after peer review from the co-faculties, 7 short clips were shown to the participants, two clips from another Hindi movie "Munnabhai MBBS" was also shown which portray professionalism. The two movies clips from the movie "Munnabhai MBBS" highlighted doctor patient relationship in context of maintaining respect of patient, colleagues and society while the other 5 movie clip from "wit" highlighted student and faculty feedback form: a questionnaire based feedback was obtained from the students and faculty about the content, effectiveness, understanding and ease of administration of the study tool, as well as the teaching sessions and their impact on the participants. Role play: a role play was designed as an assessment tool to evaluate the impact of cinema education on the knowledge and attitudes for professionalism and ethics among the students. Students were given two themes of the role-play, professionalism related to doctor patient relationship in context of maintaining respect of the patient, colleagues and society, role of informed consent and ethics committee in a clinical trial. Role play was performed by the trained faculties on these two scenarios which were observed and evaluated by the students. These included both ideal and non-ideal professional and ethical behaviour and attitudes. The students were asked to mention their observations and inferences in a pre-validated checklist that included questions like (what is the role play about?), issues (can you identify the problem? what are they?) and solution (what are the workable solutions to these problems).

\section{Procedure}

Pre-validation: pre-validation of the study tools which included pre-test, post test questionnaire, feedback form for faculties and students, movie clips and 2 role plays was done prior to conduct of the study. Sensitization: a lecture to sensitize students to principles and need for professionalism and ethics in doctors was conducted for the participating students. A hands-on training on writing reflections was conducted for the students Pre-session: the students were evaluated about the knowledge and attitudes regarding professionalism and ethics through a pre-test questionnaire. Session of cinemeducation: students were shown short movie clips that portray professionalism and ethics, after a briefing about the movie and the purpose of showing the same. Post cinemeducation session: The post session class was done on the same day as the in- session. After watching the movie the students were asked to write reflection about the movies. The students were divided in a group of 10 students and asked to discuss in group about the following points about the movie clip. They include: the positive behavioural, communication and consultation elements of health professionals they observed from the movie clip, negative behavioural, communication and consultation elements of professionalism and ethics in health professionals they observed and inferred from the movie clip, what would they do in similar situations as observed $\mathrm{n}$ the movie, how did the movie affect their feelings, beliefs, values and how do they think the movie will influence their decision-making and attitudes and behaviours in future professional and personal life. The students were then asked to present their views gathered from the discussion and one of the faculty wrote down the response of the students verbatim for evaluation later. The students also wrote their reflection individually. Feedback and post test was obtained from the students, post session. Two role plays designed as an assessment 
tool were performed by the trained faculties and observed and evaluated by students. The students were enrolled in the study as per convenience.

\section{Data interpretation and analysis}

The data was entered in Microsoft Excel sheet and analysis of the quantitative data was done using means and average. The qualitative data was analyzed using content and narrative analysis.

\section{RESULTS}

This prospective, longitudinal and interventional study was undertaken to evaluate the effect of cinemaeducation to sensitize and train undergraduate II professional medical students regarding professionalism and ethics. After validation of study tools a sensitization lecture on professionalism and ethics was taken by the investigator. Students were given hands on training to write reflection. Pre-test was taken to test baseline knowledge. Students were than shown the movie clips and assessment was done based on reflection writing, post-test, role play and feedback from students and faculties. From the pre-test it was observed that out of 139 II professional year undergraduate medical students included in the study, sixty-eight students found cinemeducation to be appropriate method to study professionalism followed by case scenario and group discussion in pre-test. While in post test 80 students preferred role play followed by cinemeducation (77) was considered the most appropriate method to study Professionalism. Sixty seven students responded that Cinemeducation was an appropriate teaching method to teach ethics to medical students in pre-test while in post test 94 students responded similarly. Responded in pretest chose Case scenarios and group discussion as the second most appropriate method followed by the role play to study Ethics. Majority students were of the opinion during the pre-test that it is important to teach professionalism (135) and ethics (133) to undergraduate medical students while 138 and 136 students responded similarly in the post-test. Three and 25 students respectively could correctly identify the four characteristics of professionalism and the four principles of Ethics correctly in the pretest.166 and 117 students were rightly able to point out that an informed consent was not required in prescribing drugs in pre and post test respectively. Ninety five students believed that Cinemeducation would help them to apply the principles of Professionalism in future while 78 opined that it also helped them to change their attitude towards colleagues and society after intervention. Post intervention, eighty eight students believed that Cinemeducation would help them apply the principles of Ethics in future while 84 believed that it also helped them change their attitude towards colleagues and society. Students were asked to reflect on the second movie clip too it. Students observed that the chief protagonist in the movie showed respect towards co-workers (96) and insisted to address patients by their name (31) rather than calling him as subject. Seventy one students reflected that all patients should be treated in a respectful manner. For the movie Wit, students reflected that taking informed consent before enrolling for a trial was a positive ethical practice (74). Presence of a female attendant at the time of examination by a doctor male gender was considered as a positive practice by 25 students. Thirty nine students observed and reflected that the attitude of the nurse in the movie was respectful as well as friendly towards patients. The rightful manner in which the nurse gave option about the DNR (Do-Not resursitate) to the patient was pointed out by 23 patients. Nine students were also able to identify the principle of Autonomy shown in the movie. The important negative points reflected by the students from Munnabhai MBBS movie was the doctor's treated patient as a subject (90 students) while 21 students observed a lack of empathy in the doctors behaviour while treating the patient. In the movie Wit, 60 students pointed out that the patient was examined by the doctor as well as resident without taking consent form her which is a negative point. Seventy-eight students pointed out that in the movie Wit the patient was not informed completely about the trial before enrolment especially about the adverse drug reactions. Fourteen students pointed out that while examining the female patient a female attendant was kept but just for formality because of which the patient felt uncomfortable. Twenty students pointed out that the doctor used medical terms to explain to the patient and not layman's language. Seven students also pointed out that the patient was not given a choice for the treatment available by the doctor.

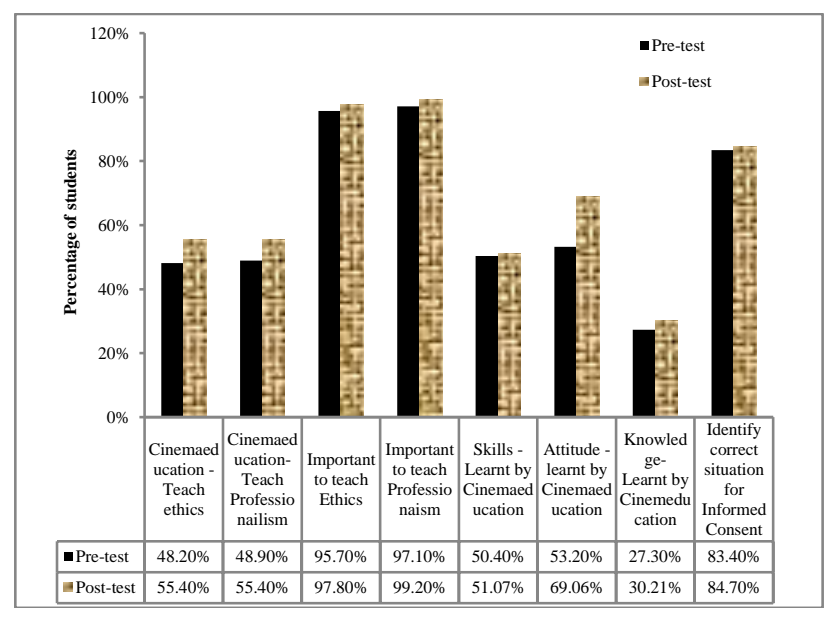

Figure 1: Pre and post test evaluation of students regarding learning professionalism and Ethics using cinemeducation.

Students were asked to reflect on what they would do in a similar situation as depicted in these movies. The students reflected that they would respect the patient (81 students), fully inform the patient about choice of treatment (61), side effects of drugs before starting the treatment (18), taken an informed consent (47), give emotional support to the patient ( 27 students), will use 
layman's language (10 students), respect patient's privacy (16 students), and will call female attendant before starting the procedure while examining a female patient (9 students). The students were asked to reflect on how both the movie clips affected their emotions. Thirty nine students reflected that the patient was treated disrespectfully and 60 students said that there should be emotional bonding with the patient.

Table 1: Feedback from students regarding learning Professionalism and Ethics using cinemeducation.

\begin{tabular}{|c|c|c|c|c|c|c|}
\hline \multicolumn{2}{|r|}{$\begin{array}{l}\text { Question number and questions } \\
(\mathbf{n}=139)\end{array}$} & \multirow{2}{*}{$\begin{array}{l}\text { Strongly } \\
\text { agree }(\%) \\
39.56\end{array}$} & \multirow{2}{*}{$\begin{array}{l}\text { Agree } \\
(\%) \\
59\end{array}$} & \multirow{2}{*}{$\begin{array}{l}\text { Neither agree/ } \\
\text { disagree }(\%) \\
1.43\end{array}$} & \multirow{2}{*}{$\begin{array}{l}\text { Disagree } \\
(\%) \\
0\end{array}$} & \multirow{2}{*}{$\begin{array}{l}\text { Strongly } \\
\text { disagree }(\%) \\
0\end{array}$} \\
\hline & $\begin{array}{l}\text { I was able to clarify my doubts about the } \\
\text { subject }\end{array}$ & & & & & \\
\hline 2 & $\begin{array}{l}\text { I had a better understanding of the subject by } \\
\text { Cinemaeducation }\end{array}$ & 53.95 & 42.45 & 2.87 & 0 & 0.72 \\
\hline 3 & $\begin{array}{l}\text { My experience with Cinema-education was } \\
\text { satisfactory }\end{array}$ & 46.04 & 50.36 & 2.16 & 0.72 & 0.72 \\
\hline \multirow{2}{*}{4} & $\begin{array}{l}\text { (a) This method will help me in developing } \\
\text { professionalism. }\end{array}$ & 39.57 & 54.68 & 5.03 & 0.72 & 0 \\
\hline & $\begin{array}{l}\text { (b) This method will help me in developing } \\
\text { ethics. }\end{array}$ & 38.85 & 55.39 & 5.75 & 0 & 0 \\
\hline \multirow{2}{*}{5} & $\begin{array}{l}\text { (a) The sessions stimulated my interest and } \\
\text { motivated me to learn about professionalism }\end{array}$ & 48.92 & 38.13 & 11.51 & 0 & 1.43 \\
\hline & $\begin{array}{l}\text { (b) The sessions stimulated my interest and } \\
\text { motivated me to learn about ethics }\end{array}$ & 43.88 & 46.76 & 7.91 & 0.72 & 0.72 \\
\hline
\end{tabular}

The students were asked to reflect on how the movie would influence their decisions in patient care, in future. The students responded that they would practice treating the patient with respect (22), calling patient by name (10), respecting the patients choice (18), following ethics and professionalism (24), respecting co-workers (17), taking consent (10), thanking patient after examination (4), respecting patient autonomy (2), keeping female attendant while examination. After the movie clips were shown, a role play was performed by the faculties and the students were asked to comment on the scenario of the role play, issues shown in the role play and possible solutions for the issues. This role play was used as assessment tool to evaluate the impact of cinema education on the knowledge and attitudes for professionalism and ethics among the students .Seventy seven students said that the role play was on clinical trial, 51 said that the scenario was on doctor patient relationship and communication, 43 said it was on informed consent, 36 said it was related to respect towards patient, 37 said it was on forcing the patient to be a part of clinical trial; and 12 said it was on patient autonomy. The issues identified by students from the role play were, incomplete information about the trial (71), forcing patient to sign (68), disrespect to patient/ staff/ other physician (88), lack of communication (42), not giving time to patient (28) and not giving patient autonomy (14).The possible solution to the issues suggested by students were to follow professionalism and ethics (42), explain patient about the trial prior to enrolment (55), give patient time to think (19), respect towards patient and staff (54), giving complete information to patient (58), complaining higher authorities (12), give choice to patient (37), keeping good behavior (31) and medical education of doctors(9).
A feedback was obtained from students and faculty regarding this teaching learning method. More than $90 \%$ students agreed that cinemeducation was able to clarify their doubts, level of understanding, their experience, the method would help them to develop professionalism and ethics, and the session stimulated their interest and motivated them to learn professionalism and ethics (Table 1). A feedback on their level of understanding about professionalism and ethics was also taken from the students. Hundred students felt that they had very good to excellent understanding on about professionalism and ninety-four had very good to excellent understanding on about Ethics after the session of cinemeducation on 0-5 point on Likert scale. After the session on cinemeducation 101 students rated themselves very good and excellent on 0-5 point on Likert scale that they will be able to practice professionalism with respect to maintaining respect for patients, colleagues and society. 100 students rated themselves very good and excellent on $0-5$ point on Likert scale that they will be able to practice ethics with respect to role of informed consent in a clinical trial. A faculty feedback $(\mathrm{N}=15)$ was mentioned that strengths of the students can have a better understanding and co-correlate the movies with real life scenario, they retain the information longer, become more engaged and also increase attention span. The drawbacks of this method as suggested by faculties were students could wrongly interpret the situation, a lot of technical support may be required and only fewer topics can be covered by this method.

\section{DISCUSSION}

Professionalism and ethics are taught passively to the students, leaving a lot of understanding to chance. 
However, over the time, it has been advocated that graduates need to be formally trained in the concepts of professionalism and ethics. ${ }^{5}$ ATCOM module has incorporated professionalism and ethics in its teaching module for IMG. Professionalism is a critical quality needed by a doctor to provide competent and compassionate care to patients. In medical profession, professionalism sets up an intrinsic value which when express outside justifies the trust that the patient have on doctors. ${ }^{6}$ As the IMG are perceived to be becoming less competent professionals specially in relation to maintaining respect towards patient, colleagues and society it has lead to a mistrust among patients as well as society. The IMG are perceived to be less competent to understand the ethical aspects of role of informed consent in a clinical research. Hence, this study was under taken to teach II professional medical students professionalism and ethics using cinema education. Movies have been used to teach medical students regarding professionalism and ethics in many counties like USA, Brazil, Israel, Korea all over the world. ${ }^{7}$ In our study the students were shown movie clips, one from a foreign movie and other an Indian movie. The use of an Indian movie represented the local context, cultural issues and familiar clinical environment of the learners. Moreover a faculty described the main theme of the triggering film. Only a part of the movie clip were used to trigger emotions and thinking of the participant and generate points of discussion without utilizing too much time. Multiple assessment methods were used like reflective writing, post-test, role play and feedback from students and faculties. Different assessments offer different perspectives and enhance reliability. ${ }^{8}$ They increase the strengths and nullify the lacunae of each method. Pre and post test assess knowledge while reflection and role play assessed their affective domain. Feedback provided corroborative evidence of benefits of the study. Our study has shown that the after the teaching learning session on cinema education more than $60 \%$ students believed that cinemeducation is an appropriate method to teach professionalism and ethics. Majority of students felt that both ethics and professionalism should be taught in under graduation itself. Approximately $60 \%$ students after seeing the movie clips felt that even attitudes can be learnt by cinemeducation. However, less than $40 \%$ students felt that knowledge as well as skills can be learned by cinemeducation. When given an example in pre as well as post test the students were able to identify the right example where an informed consent is needed. This may be because the sensitization lecture on Professionalism and Ethics was taken prior to the pre-test where even examples though not the same were explained to make the concepts clear. However, only few students were able to remember the four principles of ethics and four characteristics of professionalism in the post-test which shows that for the cognitive aspect cinemeducation should be always accompanied or preceded by a lecture. After analysis of the reflection it was found that the students were able to reflect on positive aspects like respect to patient as well as colleagues and taking an informed consent prior to examination which were the main objectives of our study. Surprisingly, they also pointed out some other aspects correctly, like greeting patient and calling patient by name, presence of a female attendant while examining a female patient by a male doctor, respecting patient's autonomy, giving patient an option of not to resuscitate as a choice when needed. Use of verbal as well as non verbal communication skills is important for doctors to effectively express that they care for the patient and also to show concern to them. ${ }^{9}$ While pointing out about the negative aspects of the movie clips about what was wrongly done by the characters of the movie they pointed that treating patients as a subject, using medical terminology while treating the patient, examination without taking informed consent from the patient, patient not completely informed details before enrolling in the trial, keeping no empathy towards patients, keeping female attendant just for formality and also examining the patient though she was uncomfortable. It is also important to point out the negative aspects so that they avoid doing mistakes in future. ${ }^{10}$ When the students were asked what would they do in similar situation they reflected that they will respect the patient, give emotional support, will use layman's language so that the patient understands doctor, keep a female attendant while examining a female patient prior to starting examination. They also reflected that they will fully inform about the details of treatment before enrolling for a clinical trial and also take informed consent prior to it. After observing the movie clip, the feelings and decisions of the student that changed were that the patient should be treated respectfully and following the professionalism and ethics is very important. The movies enhanced the students learning about their future behaviours and values while practicing medicine. The students were able to grasp the core message from the movie along with some important lesson to be learnt regarding attitude towards the patient will otherwise is difficult to teach ${ }^{11}$. They could also learn some other aspects of communication like keeping empathy towards patients how to examine a female patient using layman's language while talking to patients and respecting patient's autonomy. When the analysis was done using a role play, majority of students were able to identify scenario of the role-play related to the informed consent as an ethical aspect of a clinical trial but only 36 percent students were able to identify the scenario that the role play was dealing about doctor patient relationship. However, they were also able to point out the issues like disrespect towards patient as well as other staff members, as well as forcing patient to sign while enrolling in a trail as well as giving incomplete information about the trial. Though not exactly pointed out yet all these are important aspects of doctor patient relationship were rightly identified by students. The possible solutions given by the students regarding role play to solve such issues presented in the role-play was to give complete information to patient and treat patient in a respectful manner and follow professionalism and ethical principles. The feedback given by students about the 
understanding they got about the session was between 4 and 5 out of 5 on a 5 point Likert scale. This shows that the students felt that they were able to understand all aspects of the study. Movies are always associated with emotional component and the students were able to identify and correctly respond in dealing with such situation from the study. ${ }^{7}$ The faculties suggested that it was an appropriate method to teach professionalism and Ethics. It gave a real life scenario and made the session more engaging and increased the attention span however it needed a lot of technical support, time and cannot be used in future for all topics. Teaching professionalism and ethics as a whole are beneficial and necessary to preserve and enhance the ability of our students to meet patients' needs. ${ }^{12}$ The teaching learning session about cinemeducation helped the student about Professionalism and Ethical aspects not only the knowledge part but more regarding the attitude and communication. ${ }^{13}$ They also came to know about the role of respect and empathy while treating a patient. Movies can be used to teach professionalism and ethics as they enable the students to explore the values, beliefs and attitudes towards professionalism and Ethics. ${ }^{6}$ It should be implicated as a part of curriculum in each year to teach attitude and communication aspect about patient care. Cinemeducation is an interactive, teaching method which can be used to teach topics related to development of attitude and communications. The study had few limitations. The whole movie couldn't be shown due to time constraint. Showing a movie clip and asking them to reflect on it followed by showing other clips in session with discussing feedback simultaneously could help the students to better understand and also correct on if there were any lacunae. The sample size in our study was small to make generalized inference to teach Professionalism and ethics by cinemeducation. However, this conclusion can be better authenticated after studying in larger students and to assess again after a year to see its long term impact on students.

\section{CONCLUSION}

Professionalism and ethics has been taught by different methods in western world as a part of their curriculum. It is being experimented by several educational researchers in India too. But the use of movies to teach professionalism and ethics is not a commonly used practice. The movies enabled the students to explore the values, beliefs and attitudes towards professionalism and ethics. Cinemeducation is an interactive, teaching method which can be used to teach topics related to development of attitude and communications among medical undergraduates.

\section{Funding: No funding sources} Conflict of interest: None declared

Ethical approval: The study was approved by the Institutional Ethics Committee

\section{REFERENCES}

1. Zalika KK, Kersnik J. Using movies to teach professionalism to medical students. BMC Med Edu. 2011;11:60.

2. Jahan F, Siddiqui MA. Recognition of core elements of medical professionalism among medical students and faculty members. Oman Med J. 2016;31(3):196-204.

3. Lumlertgul N, Kijpaisalratana N, Pityaratstian N, Wangsaturaka D. Cinemeducation: A pilot student project using movies to help students learn medical professionalism. Med Teacher. 2016;31(7):e327-32.

4. Dhaliwal U, Singh S, Singh N. Reflective student narratives: honing professionalism and empathy. Indian J Med Ethics. 2018;3(1):9-15.

5. Klemenc-Ketis Z, Kersnik J. Using movies to teach professionalism to medical students. BMC Med Educ. 2011;11:60.

6. Kalasuramath SB, Vinod Kumar CS. Need of professionalism for india medical graduates: an insight. J Edu Res Med Teacher. 2016;4(1):1-5.

7. Shankar PR. Cinemeducation: Facilitating educational sessions for medical students using the power of movies. Arch Med Health Sci. 2019;7:96-103.

8. Lynch DC, Surdyk PM, Eiser AR. Assessing professionalism: a review of the literature. Med Teach. 2004;26(4):366-73.

9. Sari MI, Prabandari YS, Claramita M. Physicians' professionalism at primary care facilities from patients' perspective: The importance of doctors' communication skills. J Family Med Prim Care. 2016; 5(1):56-60.

10. Kadivar M, Mafinejad MK, Bazzaz JT, Mirzazadeh A, Jannat Z. Cinemedicine: Using movies to improve students' understanding of psychosocial aspects of medicine. Ann Med Surg (Lond). 2018;28:23-7.

11. Cruess SR, Cruess RL. Teaching professionalism why, what and how. Facts Views Vis Obgyn. 2012; 4(4):259-65.

12. Jahan F, Siddiqui MA, Al Zadjali NM, Qasim R. Recognition of Core Elements of Medical Professionalism among Medical Students and Faculty Members. Oman Med J. 2016;31(3):196-204.

13. Keskinis C, Bafitis V, Karailidou P, Pagonidou C, Pantelidis P, Rampotas A, Sideris M, Tsoulfas G, Stakos D. The use of theatre in medical education in the emergency cases school: an appealing and widely accessible way of learning. Perspect Med Educ. 2017; 6(3):199-204.

Cite this article as: Patel PP, Gandhi AM, Desai CK. Cinemeducation: a teaching-learning tool to teach professionalism and ethics in medical undergraduates. Int J Basic Clin Pharmacol 2022:11:91-6. 